\title{
Solvothermal Synthesis of $\mathrm{Bi}_{2} \mathrm{O}_{2} \mathrm{CO}_{3}$ Nanoplates for Efficient Photodegradation of RhB and Phenol under Simulated Solar Light Irradiation
}

\author{
Sheng-Peng Hu, ${ }^{\dagger, \star}$ Cheng-Yan Xu, ${ }^{\dagger, \neq, *}$ Bao-You Zhang, ${ }^{\dagger}$ Yi Pei, ${ }^{\dagger, \star}$ and Liang Zhen ${ }^{\dagger, \ldots, *}$ \\ ${ }^{\dagger}$ School of Materials Science and Engineering, Harbin Institute of Technology, Harbin 150001, China \\ ${ }^{*}$ MOE Key Laboratory of Micro-system and Micro-structures Manufacturing, Harbin Institute of Technology, \\ Harbin 150080,China. "E-mail: cy_xu@hit.edu.cn (C.-Y.Xu); lzhen@hit.edu.cn(L. Zhen) \\ Received February 15, 2014, Accepted June 8, 2014
}

\begin{abstract}
Monodispersed $\mathrm{Bi}_{2} \mathrm{O}_{2} \mathrm{CO}_{3}$ nanoplates with an average width of $320 \mathrm{~nm}$ and thicknesses of $50-90 \mathrm{~nm}$ were successfully synthesized by a simple solvothermal method in a mixture solution of polyethylene glycol and $\mathrm{H}_{2} \mathrm{O}$. The obtained nanoplates were characterized by means of XRD, FT-IR, SEM and TEM. The effect of surfactant sodium dodecyl benzene sulfonate on the morphology of $\mathrm{Bi}_{2} \mathrm{O}_{2} \mathrm{CO}_{3}$ product was investigated. Under simulated solar light irradiation, $\mathrm{Bi}_{2} \mathrm{O}_{2} \mathrm{CO}_{3}$ nanoplates exhibited superior photocatalytic activities towards the degradation of $\mathrm{RhB}$ as well as high chemical stability upon cycling photocatalytic test. The nanoplates also showed promising photodegradation ability for eliminating refractory pollutant of phenol. The excellent photocatalytic performance of $\mathrm{Bi}_{2} \mathrm{O}_{2} \mathrm{CO}_{3}$ nanoplates as compared with $\mathrm{P} 25-\mathrm{TiO}_{2}$ endows them as promising high efficiency photocatalysts.
\end{abstract}

Key Words : $\mathrm{Bi}_{2} \mathrm{O}_{2} \mathrm{CO}_{3}$, Semiconductor photocatalyst, Solvothermal synthesis

\section{Introduction}

Semiconductor photocatalysts have been focused in recent years due to their attractive applications in solar energy conversion and degradation of organic pollutants, which are crucial for sustainable development considering of environmental issues. ${ }^{1,2}$ As a novel kind of photocatalysts, bismuth-containing semiconductors have recently attracted increasingly attention due to their high activities towards the photodegradation of organic dyes as well as good stability. ${ }^{3-7}$ Recently, Xie et al. ${ }^{8}$ reported the photocatalytic activity of flower-like hierarchitecture of bismuth subcarbonate $\left(\mathrm{Bi}_{2} \mathrm{O}_{2} \mathrm{CO}_{3}\right)$, a commonly-used potent antibacterial agent, under solar light irradiation using rhodamine $\mathrm{B}(\mathrm{RhB})$ as a model organic pollutant. The subsequent work were dedicated to the correlation between the photocatalytic performance and structure characteristics of the material, and various morphologies of $\mathrm{Bi}_{2} \mathrm{O}_{2} \mathrm{CO}_{3}$ have been synthesized, such as nanosheets, ${ }^{9}$ nanotubes, ${ }^{10}$ microspheres, ${ }^{11,12}$ and flower-like hierarchitectures. ${ }^{13,14}$ The reported $\mathrm{Bi}_{2} \mathrm{O}_{2} \mathrm{CO}_{3}$ showed high activities in degrading organic dyes such as methylene blue (MB) and methyl orange (MO), as well as in removing heavy metal ions.

In recent years, two-dimensional (2D) nanomaterials have attracted considerable attention owing to their unique electronic and optical properties, as well as their promising applications in water splitting and environmental purification. ${ }^{15-17}$ Zhu et $a l^{18}$ developed a simple hydrothermal process to synthesis square $\mathrm{Bi}_{2} \mathrm{WO}_{6}$ nanoplates, which exhibited high photocatalytic activities under visible light irradiation. Jiang et al..$^{19}$ selectively synthesized $\mathrm{BiOCl}$ single-crystalline nanosheets with exposed $\{001\}$ and $\{010\}$ facets via a facile hydrothermal route. Zhang et al. ${ }^{20}$ synthesized $\mathrm{BiOBr}$ nano- sheets with thicknesses ranging from 9 to $32 \mathrm{~nm}$ by a facile and surfactant-free method, which shown higher photocatalytic activity to $\mathrm{RhB}$ under visible-light irradiation.

$\mathrm{Bi}_{2} \mathrm{O}_{2} \mathrm{CO}_{3}$ is a typical "Sillén" phase, in which Bi-O layers and $\left(\mathrm{CO}_{3}\right)$ layers are inter-grown with the plane of the $\left(\mathrm{CO}_{3}\right)$ group orthogonal to the plane of the Bi-O layer. ${ }^{21,22}$ The internal layered structure of $\mathrm{Bi}_{2} \mathrm{O}_{2} \mathrm{CO}_{3}$ would guide the lower growth rate along certain axis compared with that for other axes, to form 2D morphologies such as sheet-like or plate-like products. ${ }^{8,23,24}$ Previous work has demonstrated that $\mathrm{Bi}_{2} \mathrm{O}_{2} \mathrm{CO}_{3}$ hierarchical structures assembled by nanosheets exhibit high activity towards the photodegradation of $\mathrm{RhB}$ as well as the mixed solution of MB and MO, due to their exposed (001) facets. ${ }^{12}$ Herein, we reported a facile solvothermal approach to the synthesis of monodispersed $\mathrm{Bi}_{2} \mathrm{O}_{2} \mathrm{CO}_{3}$ nanoplates with an average thickness of about 70 $\mathrm{nm}$. The as-synthesized $\mathrm{Bi}_{2} \mathrm{O}_{2} \mathrm{CO}_{3}$ nanoplates exhibited excellent photocatalytic activity towards the degradation of $\mathrm{RhB}$ and refractory phenol under simulated solar light (SSL) irradiation.

\section{Experimental}

In a typical synthesis procedure, $0.5 \mathrm{mmol}$ of $\mathrm{Bi}\left(\mathrm{NO}_{3}\right)_{3} \cdot 5 \mathrm{H}_{2} \mathrm{O}$ was dissolved into $10 \mathrm{~mL}$ of polyethylene glycol (PEG 200). Various amounts of sodium dodecyl benzene sulfonate (SDBS) were dissolved into $25 \mathrm{~mL}$ of distilled water. The two solutions were fully mixed under magnetic stirring, and then transferred into a Teflon-lined stainless steel autoclave with $50 \mathrm{~mL}$ capacity. The reaction temperature was kept at $180^{\circ} \mathrm{C}$ for $20 \mathrm{~h}$, then the autoclave was allowed to cooling down to room temperature naturally. The precipitate was collected and washed with distilled water and ethanol for 
several times, and then dried at $60{ }^{\circ} \mathrm{C}$ in air.

The obtained product was characterized by X-ray diffraction (XRD, Rigaku D/max 2500 diffractometer with $\mathrm{Cu} \mathrm{K}$ radiation), scanning electron microscope (SEM, FEI Quanta 200F), transmission electron microscope (TEM, JEOL JEM2100), and Fourier transform infrared spectrum (FT-IR, Shimadzu IRAffinity-1). UV-vis diffuse reflectance spectrum of the powder samples was recorded on a Shimadzu UV2550 spectrometer.

$\mathrm{RhB}$ and phenol were selected as model pollutants to evaluate the photocatalytic activity of $\mathrm{Bi}_{2} \mathrm{O}_{2} \mathrm{CO}_{3}$ nanoplates. The detailed experimental setup could be found in previous work. ${ }^{25}$ The concentrations of $\mathrm{RhB}$ and phenol solutions are $1.0 \times 10^{-5} \mathrm{M}$ and $20 \mathrm{mg} / \mathrm{L}$, respectively. The light source is a 300W Xenon lamp (Beijing Aulight, China).

\section{Results and Discussion}

Characterization of $\mathrm{Bi}_{2} \mathrm{O}_{2} \mathrm{CO}_{3}$ Nanoplates. The phase and purity of the as-synthesized product were determined by $\mathrm{XRD}$, and the results were shown in Figure 1. All the diffraction peaks can be perfectly indexed to the tetragonal $\mathrm{Bi}_{2} \mathrm{O}_{2} \mathrm{CO}_{3}$ with lattice parameters of $a=b=3.865 \AA$, and $c=$ $13.675 \AA$ (JCPDS 41-1488). The strong and narrow diffraction peaks indicate that the as-synthesized product has been well crystallized. Compared with the relative intensity of diffraction lines shown in the standard JCPDS card (low panel in Figure 1), the (004) and (006) diffraction intensities of $\mathrm{Bi}_{2} \mathrm{O}_{2} \mathrm{CO}_{3}$ nanoplates are high, suggesting that the asprepared products have a preferred $(001)$ orientation. Fourier transform infrared spectrum (FT-IR) of as-synthesized $\mathrm{Bi}_{2} \mathrm{O}_{2} \mathrm{CO}_{3}$ nanoplates is shown in Figure 2. The carbonate ions possess four internal vibrations: symmetric stretching mode $v_{1}$, corresponding anti-symmetric vibration $v_{2}$, the outof plane bending mode $v_{3}$ and the in-plane deformation $v_{4}{ }^{26,27}$ The observed peaks centered at 1067, 846 and 820, 1391 and 1468 and $670 \mathrm{~cm}^{-1}$ are associated with the $v_{1}, v_{2}$, $v_{3}, v_{4}$ vibration modes of the $\mathrm{CO}_{3}{ }^{2-}$ group, respectively. The

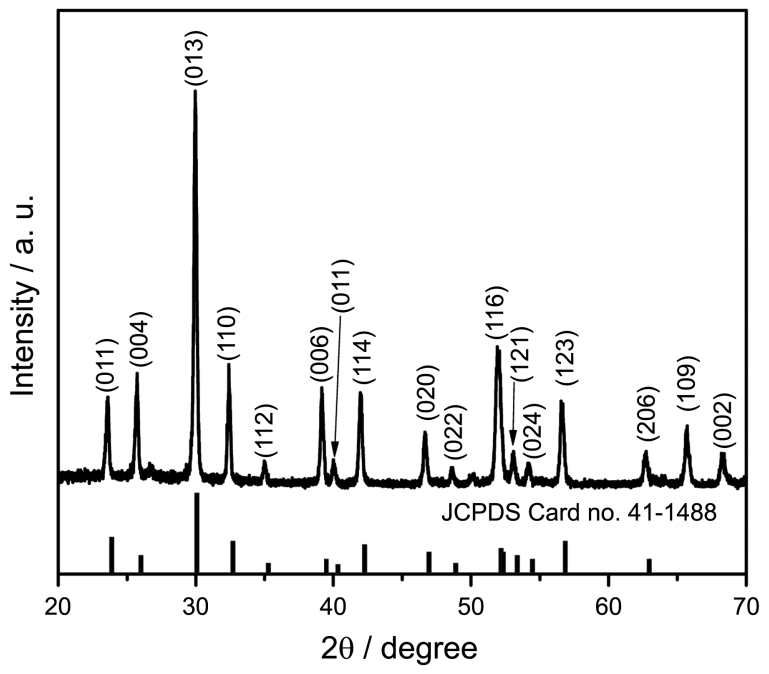

Figure 1. XRD pattern of as-synthesized $\mathrm{Bi}_{2} \mathrm{O}_{2} \mathrm{CO}_{3}$ product. The low panel shows diffraction lines from standard JCPDS card.

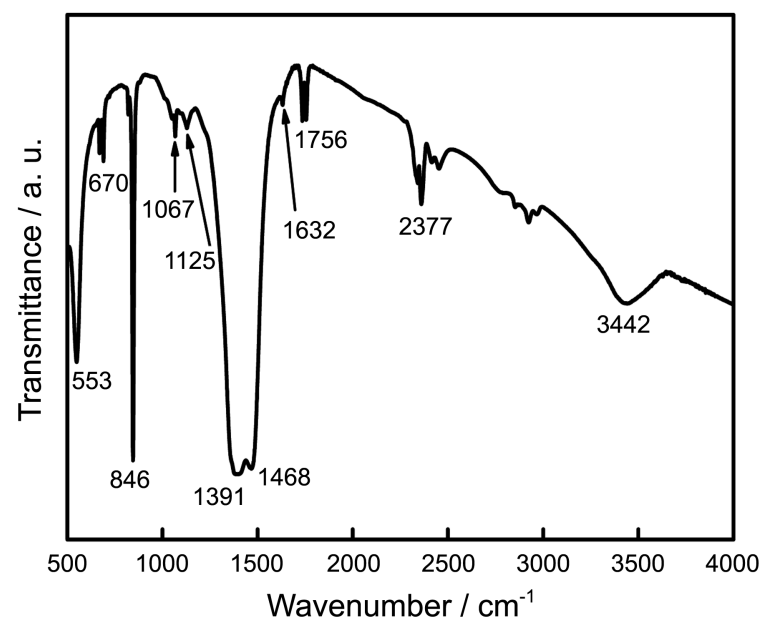

Figure 2. FT-IR spectrum of the as-synthesized $\mathrm{Bi}_{2} \mathrm{O}_{2} \mathrm{CO}_{3}$ product.

absorption peak centered at $1756 \mathrm{~cm}^{-1}$ is assigned to the $\left(v_{1}+\right.$ $v_{4}$ ) mode of the $\mathrm{CO}_{3}{ }^{2-}$ group. In addition, the broad bands centered at 3442 and $2377 \mathrm{~cm}^{-1}$ are assigned to the stretching vibrations of hydroxyl groups. ${ }^{27}$ The absorption peak centered at $553 \mathrm{~cm}^{-1}$ is attributed to Bi-O stretching mode.

Figure 3(a) and (b) show typical SEM images of $\mathrm{Bi}_{2} \mathrm{O}_{2} \mathrm{CO}_{3}$ product at different magnifications. Monodispersed nanoplates with an average width of about $320 \mathrm{~nm}$ were obtained by current solvothermal method. The thicknesses of $\mathrm{Bi}_{2} \mathrm{O}_{2} \mathrm{CO}_{3}$ nanoplates range from 50 to $90 \mathrm{~nm}$, as seen from highmagnification SEM image (Figure 3(b)). TEM image shown in Figure 3(c) display the irregular polygon shapes of the nanoplates. The low aspect ratio of $\mathrm{Bi}_{2} \mathrm{O}_{2} \mathrm{CO}_{3}$ nanoplates results in a few standing plates during both SEM and TEM observations. Selected-area electron diffraction (SAED) pattern of an individual $\mathrm{Bi}_{2} \mathrm{O}_{2} \mathrm{CO}_{3}$ nanoplate is presented in the inset of Figure 3(c). Indexing of the electron diffraction pattern also suggests the preferred (001) orientation, namely, exposed (001) facet that endow the nanoplates tend to lie on the holy carbon film during TEM observation. Figure $3(\mathrm{~d})$ is
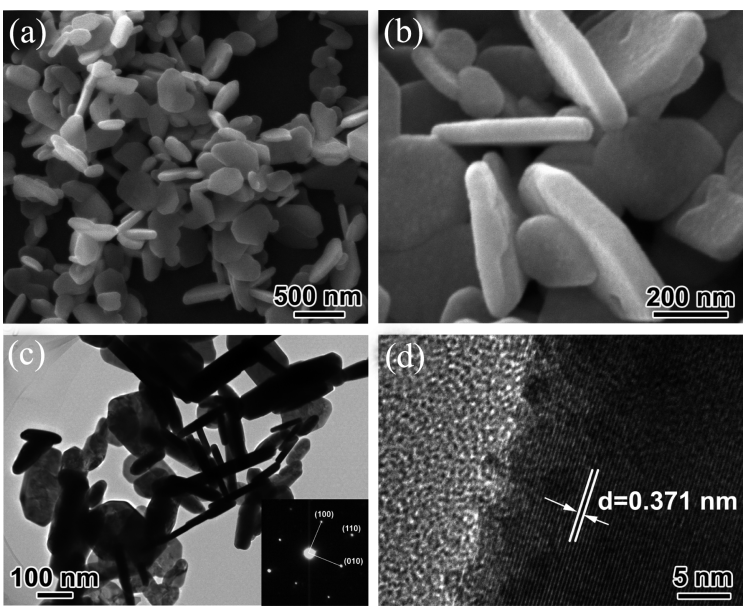

Figure 3. (a, b) SEM images, (c) TEM image, and (d) HRTEM image of the obtained $\mathrm{Bi}_{2} \mathrm{O}_{2} \mathrm{CO}_{3}$ nanoplates. Inset in (c) is SAED pattern of an individual $\mathrm{Bi}_{2} \mathrm{O}_{2} \mathrm{CO}_{3}$ nanoplate. 
(a)
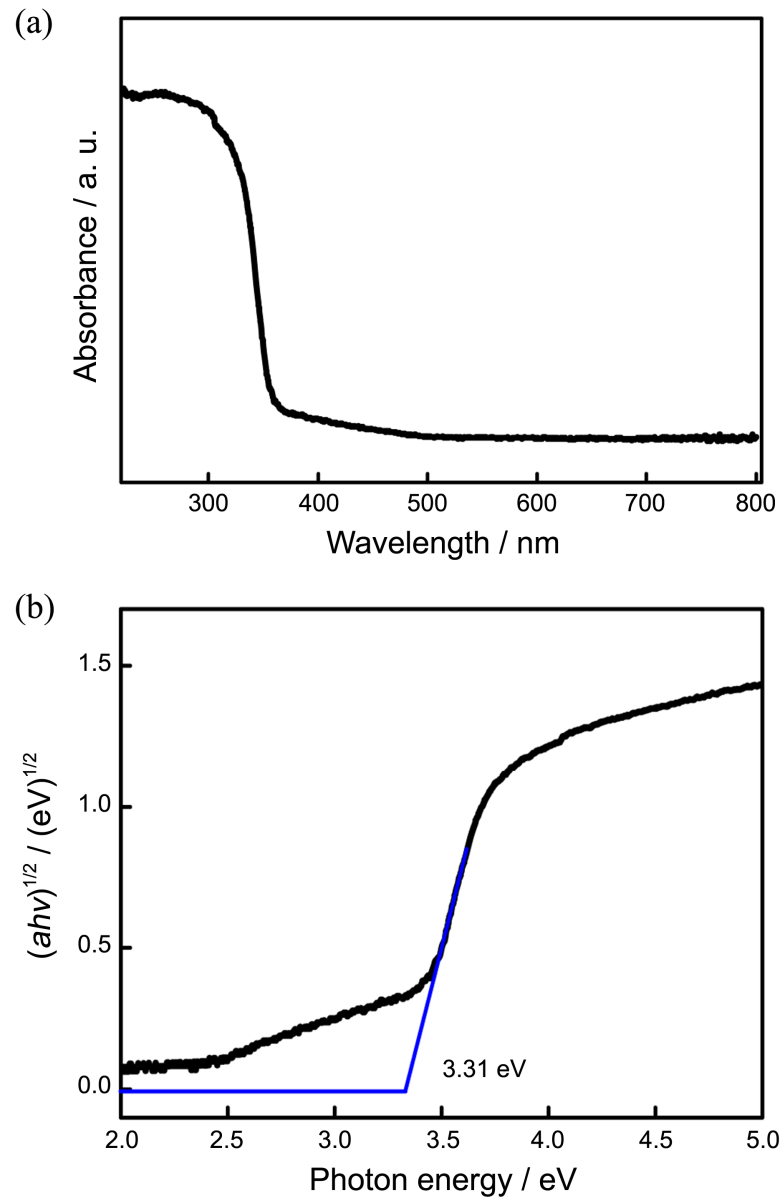

Figure 4. (a) UV-vis diffuse reflectance spectrum and (b) plot of the $(a h v)^{1 / 2} v s$. photon energy $(h v)$ of $\mathrm{Bi}_{2} \mathrm{O}_{2} \mathrm{CO}_{3}$ nanoplates.

the high-resolution transmission electron microscope (HRTEM) image of $\mathrm{Bi}_{2} \mathrm{O}_{2} \mathrm{CO}_{3}$ nanoplates, illustrating the singlecrystalline nature of the plates. The well-resolved lattice fringe of $0.371 \mathrm{~nm}$ can be assigned to the (011) crystallographic plane spacing of $\mathrm{Bi}_{2} \mathrm{O}_{2} \mathrm{CO}_{3}$.

The optical absorption characteristic of $\mathrm{Bi}_{2} \mathrm{O}_{2} \mathrm{CO}_{3}$ nanoplates was evaluated by UV-vis diffuse reflectance spectrum (Figure 4(a)), showing the strong absorption at UV region. The band gap of semiconductors can be estimated according the equation:

$$
A h v=A\left(h v-E_{g}\right)^{n / 2}
$$

where $n$ is determined by the characteristics of the transition in a semiconductor. For $\mathrm{Bi}_{2} \mathrm{O}_{2} \mathrm{CO}_{3}, n$ equals to 4 for indirect transition. ${ }^{8,23,24,28}$ From the onset of the absorption edge (Figure $4 \mathrm{~b}$ ), the band gaps can be estimated from the plot of $(\alpha h v)^{1 / 2}$ versus photo energy $(h v)$. The band gap of $\mathrm{Bi}_{2} \mathrm{O}_{2} \mathrm{CO}_{3}$ nanoplates is calculated to be about $3.31 \mathrm{eV}$. The suitable bandgap makes $\mathrm{Bi}_{2} \mathrm{O}_{2} \mathrm{CO}_{3}$ sample as a potential photocatalyst for the degradation of organic pollutants under solar light irradiation.

Effect of SDBS Amounts on the Formation of $\mathrm{Bi}_{2} \mathrm{O}_{\mathbf{2}} \mathrm{CO}_{3}$ Nanoplates. The anisotropic growth of $\mathrm{Bi}_{2} \mathrm{O}_{2} \mathrm{CO}_{3}$ nanoplates might be due to the inherent layer structure, ${ }^{8}$ but its
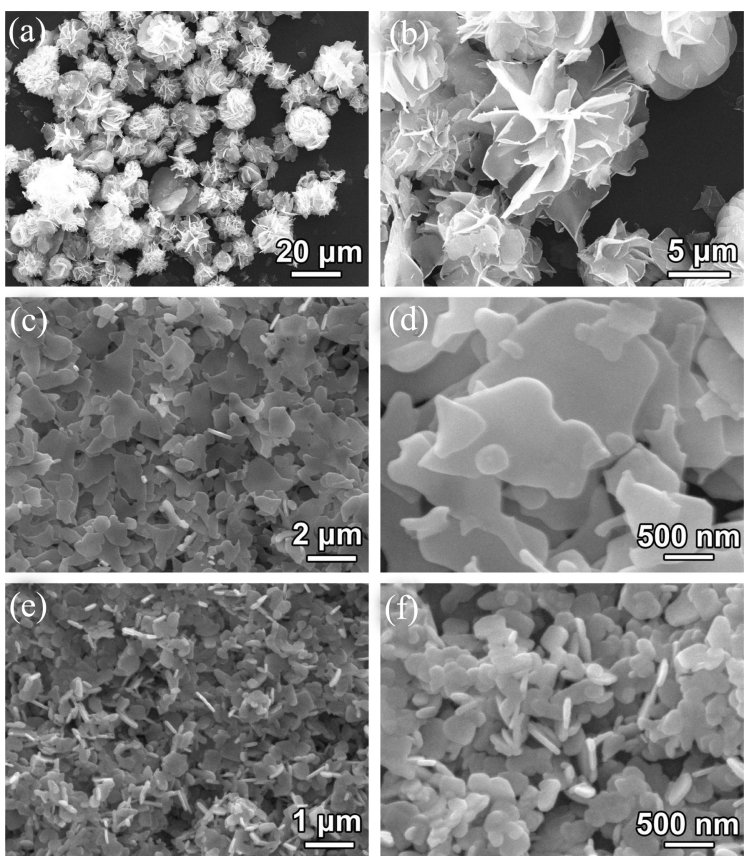

Figure 5. SEM images of $\mathrm{Bi}_{2} \mathrm{O}_{2} \mathrm{CO}_{3}$ products synthesized with different amounts of SDBS: (a, b) without SDBS; (c, d) $0.2 \mathrm{~g}$; (e, f) $1.0 \mathrm{~g}$.

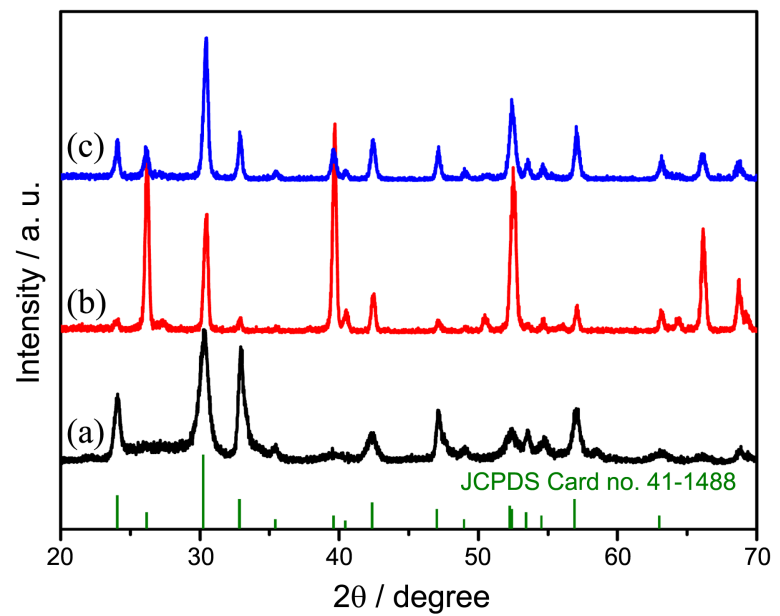

Figure 6. XRD patterns of $\mathrm{Bi}_{2} \mathrm{O}_{2} \mathrm{CO}_{3}$ products synthesized with different amounts of SDBS: (a) without SDBS; (b) $0.2 \mathrm{~g}$; (c) $1.0 \mathrm{~g}$.

morphology also lies on the amount of SDBS. To fully understand the effect of SDBS on the formation of the $\mathrm{Bi}_{2} \mathrm{O}_{2} \mathrm{CO}_{3}$ nanoplates, experiments with different amounts of SDBS were carried out while keeping other reaction conditions identical. Figures 5 and 6 give SEM images and XRD patterns of $\mathrm{Bi}_{2} \mathrm{O}_{2} \mathrm{CO}_{3}$ products under different SDBS amounts $(0,0.2$ and $1 \mathrm{~g})$. The results indicate that SDBS plays a key role in determining the morphology of $\mathrm{Bi}_{2} \mathrm{O}_{2} \mathrm{CO}_{3}$ product. In the absence of SDBS, flower-like products with diameter of 5-20 $\mu \mathrm{m}$ rather than monodispersed plates were obtained (Figure 5(a)). High-magnification SEM image (Figure 5(b)) of the sample shows that the flower-like product is composed of nanosheets with thickness of 10-30 nm; and the broaden diffraction peaks of XRD pattern also demon- 
(a)

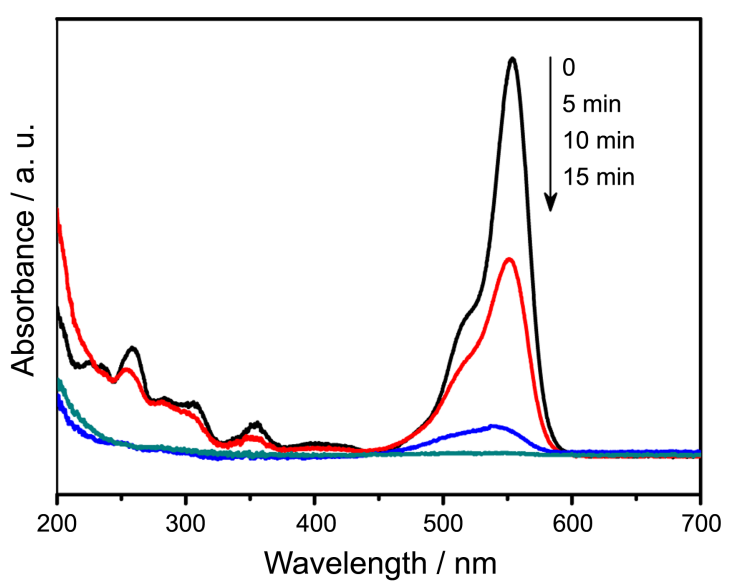

(b)

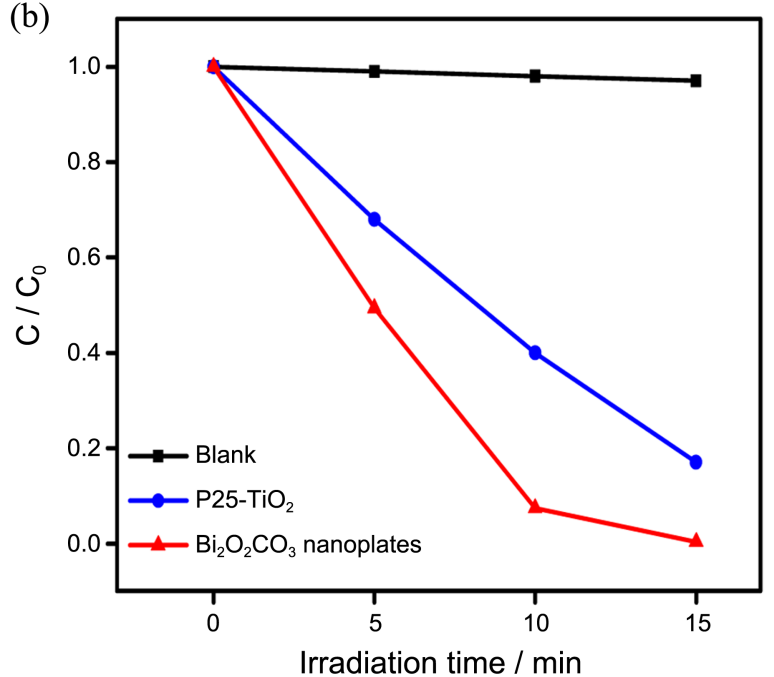

Figure 7. (a) Temporal evolution of the absorption spectra of $\mathrm{RhB}$ solution in the presence of $\mathrm{Bi}_{2} \mathrm{O}_{2} \mathrm{CO}_{3}$ nanoplates under SSL irradiation. (b) Changes of $\mathrm{RhB}$ solution concentration as a function of irradiation time in the presence of $\mathrm{Bi}_{2} \mathrm{O}_{2} \mathrm{CO}_{3}$ nanoplates and $\mathrm{P} 25-\mathrm{TiO}_{2}$. Blank experiment data is presented as a reference.

strate the nano-size of the building-blocks (Figure 6(a)). In the absence of SDBS, $\mathrm{Bi}_{2} \mathrm{O}_{2} \mathrm{CO}_{3}$ phase will be formed through the reaction between $\mathrm{Bi}^{3+}$ ions and $\mathrm{CO}_{3}{ }^{2-}$ anions originates from air. And the formation of plate-like structures should be related to the slow reaction controlled by Bi-PEG200 complex. ${ }^{29-32}$ With a small amount of SDBS $(0.2 \mathrm{~g}), \mathrm{Bi}_{2} \mathrm{O}_{2} \mathrm{CO}_{3}$ nanoplates with irregular shapes were obtained (Figure 5(c) and (d)). The corresponding XRD pattern (Figure 6(b)) also presents the relative high diffraction intensity of (004) and (006) facets, indicating a preferred orientation. Further increasing the amount of SDBS $(1.0 \mathrm{~g})$ would produce $\mathrm{Bi}_{2} \mathrm{O}_{2} \mathrm{CO}_{3}$ nanoplates with small size of c.a. $200 \mathrm{~nm}$ and thickness of c.a. $60 \mathrm{~nm}$ (Figure 5(e) and (f)). Therefore, introducing a certain amount of SDBS into the reaction system would promote the formation of $\mathrm{Bi}_{2} \mathrm{O}_{2} \mathrm{CO}_{3}$ nanoplates. It is widely accepted that organic surfactants in solutions serve as the capping agents, chelating agents or soft templates, which play key roles in the synthesis of micro/nanostructures with different shapes and sizes. ${ }^{32-35}$

Similar to previous studies, SDBS could adsorb on the surface of $\mathrm{Bi}_{2} \mathrm{O}_{2} \mathrm{CO}_{3}$ nanoparticles during the growing process, which changes the growth rate of crystal facets and then tailors the crystal shape, resulting in the final formation of nanoplates. The size decreasing of nanoplates is related to the fact that high amounts of SDBS not only adsorb the crystal face but also increase the viscosity of the reaction solutions. ${ }^{35}$ Higher viscosity will decrease the diffusion leading to the formation of nanoplates with small sizes.

Photocatalytic Performance. It is accepted that 2D nanomaterials possessed excellent photocatalytic performance because of their unique electronic and optical properties. Owing to the band gap and better spectral response of $\mathrm{Bi}_{2} \mathrm{O}_{2} \mathrm{CO}_{3}$ nanoplates, the sample is used to degrade contaminants under solar light irradiation. Figure 7(a) displays the temporal evolution of absorption spectra of $\mathrm{RhB}$ solution in the presence of $\mathrm{Bi}_{2} \mathrm{O}_{2} \mathrm{CO}_{3}$ nanoplates under SSL irradiation. The characteristic absorption peak of $\mathrm{RhB}$ at $553 \mathrm{~nm}$ diminishes rapidly within $15 \mathrm{~min}$, suggesting the supervisor photocatalytic activity of $\mathrm{Bi}_{2} \mathrm{O}_{2} \mathrm{CO}_{3}$ nanoplates as compared with commercial $\mathrm{P}_{25}-\mathrm{TiO}_{2}$ (Figure 7(b)) and previous work. ${ }^{8,9}$

As for the practical applications in aqueous solution such as waste water purification, the recycling of photocatalysts is

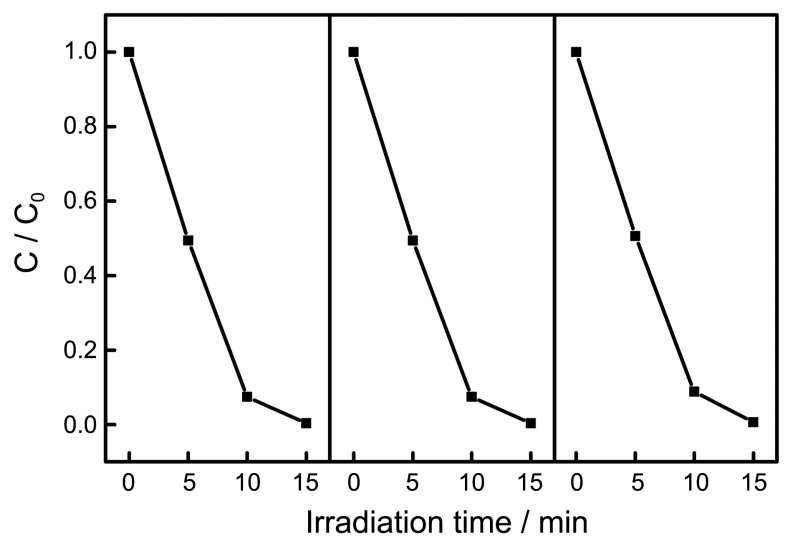

Figure 8. Cyclability of photocatalytic activity of $\mathrm{Bi}_{2} \mathrm{O}_{2} \mathrm{CO}_{3}$ nanoplates for the degradation of $\mathrm{RhB}$ under SSL irradiation.

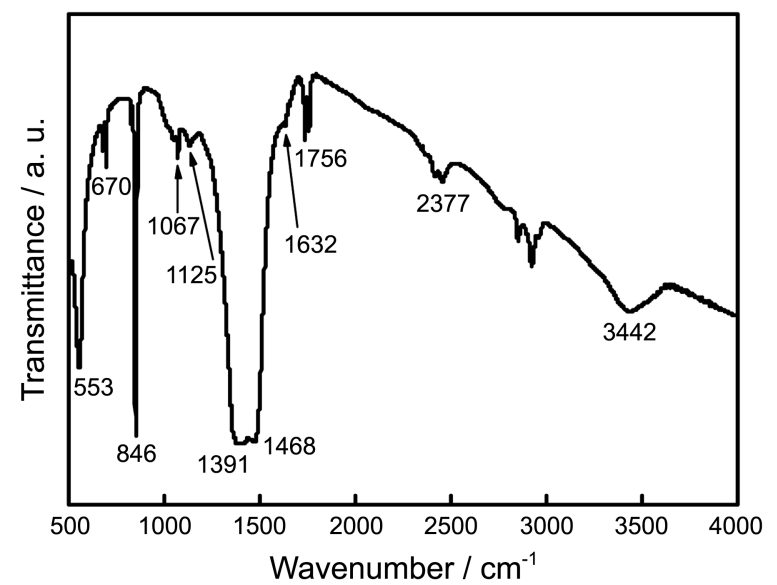

Figure 9. FT-IR spectrum of $\mathrm{Bi}_{2} \mathrm{O}_{2} \mathrm{CO}_{3}$ nanoplates after 3 cycles of $\mathrm{RhB}$ photocatalytic degradation. 
of great significance. The $\mathrm{Bi}_{2} \mathrm{O}_{2} \mathrm{CO}_{3}$ nanoplates were reused for photodegradation cycle reaction under the same condition, and the results are shown in Figure 8. The efficiency remains the same after 3 cycles. FT-IR spectrum of the cycled sample (Figure 9) is almost the same as that of the pristine nanoplates. These results clearly indicate that $\mathrm{Bi}_{2} \mathrm{O}_{2} \mathrm{CO}_{3}$ nanoplates are chemically stable as high activity photocatalyst under SSL irradiation.

In view of the practical applications of photocatalysts, a typical refractory organic pollutant, phenol, is selected as another model pollutant to evaluate the potential usage of $\mathrm{Bi}_{2} \mathrm{O}_{2} \mathrm{CO}_{3}$ nanoplates. As shown in Figure 10(a), the intensity of characteristic absorption peak of phenol at $269 \mathrm{~nm}$ decreases gradually with the increase of irradiation time, and the absorbance of phenol decreases by $\sim 100 \%$ within 160 min (Figure 10(b)). As a comparison, the degradation ratio of $\mathrm{P} 25-\mathrm{TiO}_{2}$ reaches only $40 \%$ with identical conditions (Figure 10(b)). This suggests that $\mathrm{Bi}_{2} \mathrm{O}_{2} \mathrm{CO}_{3}$ nanoplates are rather attractive as a novel photocatalyst towards the degradation of refractory organics.

The superior photocatalytic activity of $\mathrm{Bi}_{2} \mathrm{O}_{2} \mathrm{CO}_{3}$ nanoplates, as compared with commercial $\mathrm{P} 25-\mathrm{TiO}_{2}$, is mainly

(a)

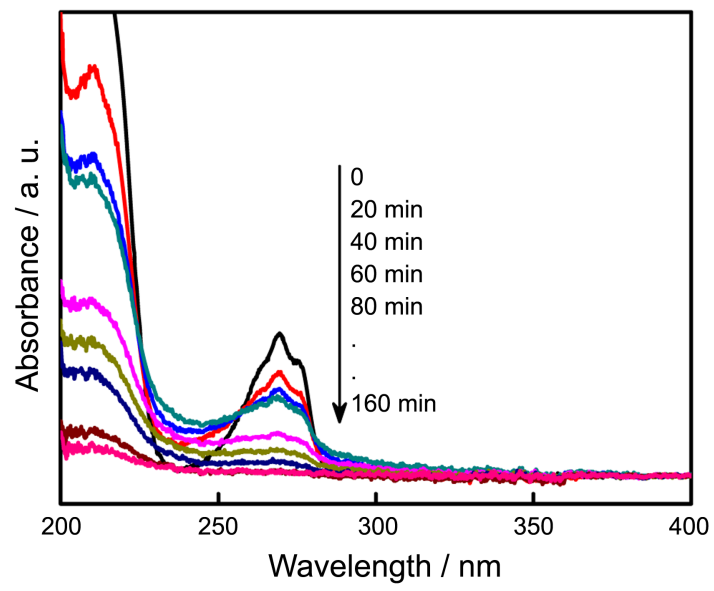

(b)

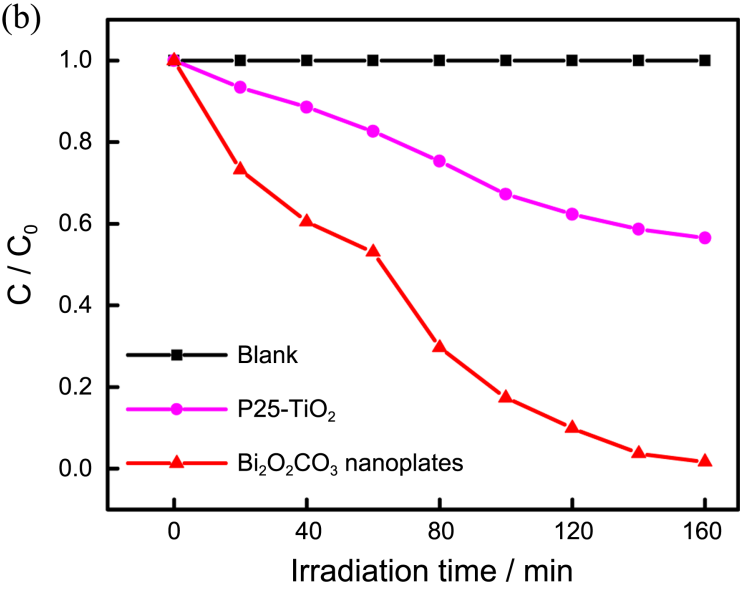

Figure 10. (a) Temporal evolution of the absorption spectra of phenol solution in the presence of $\mathrm{Bi}_{2} \mathrm{O}_{2} \mathrm{CO}_{3}$ nanoplates under SSL irradiation. (b) Changes of phenol solution concentration as a function of irradiation time in the presence of $\mathrm{Bi}_{2} \mathrm{O}_{2} \mathrm{CO}_{3}$ nanoplates and $\mathrm{P} 25-\mathrm{TiO}_{2}$. Blank experiment data is presented as a reference. attributed to the higher valence band of $\mathrm{Bi}_{2} \mathrm{O}_{2} \mathrm{CO}_{3}$ structure, ${ }^{12,36}$ namely, $3.31 \mathrm{eV}$ for $\mathrm{Bi}_{2} \mathrm{O}_{2} \mathrm{CO}_{3}$ vs. $3.2 \mathrm{eV}$ for anatase and 3.0 $\mathrm{eV}$ for rutile. The higher band gap means higher oxidation ability of photo-generated holes, which is reasonable that the photocatalytic activity of $\mathrm{Bi}_{2} \mathrm{O}_{2} \mathrm{CO}_{3}$ is better than that of $\mathrm{P} 25-\mathrm{TiO}_{2}$. The other reason is assigned to the exposed (001) facet of $\mathrm{Bi}_{2} \mathrm{O}_{2} \mathrm{CO}_{3}$ nanoplates, which could supply more oxygen defects to generate electron and vacancy under SSL irradiation. ${ }^{8}$ The nanoscale two-dimensional characteristic also ensures high carrier mobility and large contact area between the photocatalyst and organic pollutants. ${ }^{2,6,37,38}$

\section{Conclusions}

In summary, we have developed a simple solvothermal approach for the synthesis of uniform $\mathrm{Bi}_{2} \mathrm{O}_{2} \mathrm{CO}_{3}$ nanoplates as a novel photocatalyst. The anisotropic growth of $\mathrm{Bi}_{2} \mathrm{O}_{2} \mathrm{CO}_{3}$ nanoplates might be due to the inherent layer structure, but suitable amount of SDBS is indispensable for achieving uniform nanoplates. The obtained $\mathrm{Bi}_{2} \mathrm{O}_{2} \mathrm{CO}_{3}$ nanoplates exhibit high activity towards the photocatalytic degradation of organic pollutants ( $\mathrm{RhB}$ and phenol) under simulated solar light irradiation, as well as good chemical stability. Thus, the obtained $\mathrm{Bi}_{2} \mathrm{O}_{2} \mathrm{CO}_{3}$ nanoplates are considered as promising high efficiency photocatalysts for practical applications.

Acknowledgments. This work was financially supported by Open Funds of MOE Key Laboratory of Micro-systems and Micro-structures Manufacturing. C.Y.X. acknowledges the Fundamental Research Funds for the Central Universities (HIT.BRETIII. 201203).

\section{References}

1. Chen, C.; Ma, W.; Zhao, J. Chem. Soc. Rev. 2010, 39, 4206.

2. Hu, X.; Li, G.; Yu, J. C. Langmuir 2010, 26, 3031.

3. Kudo, A.; Miseki, Y. Chem. Soc. Rev. 2009, 38, 253.

4. Chen, X.; Shen, S.; Guo, L.; Mao, S. S. Chem. Rev. 2010, 110, 6503.

5. Zhang, L.; Wang, H.; Chen, Z.; Wong, P. K.; Liu, J. Appl. Catal. B 2011, 106, 1 .

6. Tong, H.; Ouyang, S.; Bi, Y.; Umezawa, N.; Oshikiri, M.; Ye, J. Adv. Mater. 2012, 24, 229.

7. Cao, J.; Xu, B.; Lin, H.; Luo, B.; Chen, S. Dalton Trans. 2012, 41, 11482.

8. Zheng, Y.; Duan, F.; Chen, M. Q.; Xie, Y. J. Mol. Catal. A: Chem. 2010, 317,34

9. Liu, Y. Y.; Wang, Z. Y.; Huang, B. B.; Yang, K. S.; Zhang, X. Y.; Qin, X. Y.; Dai, Y. Appl. Surf. Sci. 2010, 257, 172.

10. Qin, F.; Li, G. F.; Wang, R. M.; Wu, J. L.; Sun, H. Z.; Chen, R. Chem. Eur. J. 2012, 18, 16491.

11. Zhao, T. Y.; Zai, J. T.; Xu, M.; Zou, Q.; Su, Y. Z.; Wang, K. X.; Qian, X. F. CrystEngComm 2011, 13, 4010.

12. Madhusudan, P.; Zhang, J.; Cheng, B.; Liu, G. CrystEngComm 2013, 15, 231

13. Chen, L.; Huang, R.; Yin, S. F.; Luo, S. L.; Au, C. T. Chem. Eng. J. 2012, 193, 123.

14. Cheng, H. F.; Huang, B. B.; Yang, K. S.; Wang, Z. Y.; Qin, X. Y.; Zhang, X. Y.; Dai, Y. ChemPhysChem 2010, 11, 2167.

15. Pacchioni, G. Chem. Eur. J. 2012, 18, 10144.

16. Xu, M.; Liang, T.; Shi, M.; Chen, H. Chem. Rev. 2013, 113, 3766. 
17. An, X.; Yu, J. C.; Wang, F.; Li, C.; Li, Y. Appl. Catal. B 2013, 129, 808.

18. Zhang, C.; Zhu, Y. Chem. Mater. 2005, 17, 3537.

19. Jiang, J.; Zhao, K.; Xiao, X.; Zhang, L. J. Am. Chem. Soc. 2012, $134,4473$.

20. Zhang, D.; Li, J.; Wang, Q.; Wu, Q. J. Mater. Chem. A 2013, 1, 8622 .

21. Greaves, C.; Blower, S. K. Mater. Res. Bull. 1988, 23, 1001.

22. Grice, J. D. Can. Mineral. 2002, 40, 693.

23. Chen, R.; Cheng, G.; So, M. H.; Wu, J.; Lu, Z.; Che, C.-M.; Sun, H. Mater. Res. Bull. 2010, 45, 654 .

24. Madhusudan, P.; Zhang, J.; Cheng, B.; Liu, G. CrystEngComm 2013, $15,231$.

25. Hu, S. P.; Xu, C. Y.; Zhen, L. Mater. Lett. 2013, 95, 117.

26. Dong, F.; Ho, W. K.; Lee, S. C.; Wu, Z.; Fu, M.; Zou, S.; Huang, Y. J. Mater. Chem. 2011, 21, 12428.

27. Madhusudan, P.; Yu, J.; Wang, W.; Cheng, B.; Liu, G. Dalton Trans. 2012, 41, 14345.
28. Peng, S.; Li, L.; Tan, H.; Wu, Y.; Cai, R.; Yu, H.; Huang, X.; Zhu, P.; Ramakrishna, S.; Srinivasan, M.; Yan, Q. J. Mater. Chem. A 2013, 1,7630 .

29. Liu, G.; Yu, J. C.; Lu, G. Q.; Cheng, H. M. Chem. Commun. 2011, 6763.

30. Zhao, H.; Yin, W.; Zhao, M.; Song, Y.; Yang, H. Appl. Catal. B 2013, 130-131, 178.

31. Zhang, L.; Zhu, Y. Catal. Sci. Technol. 2012, 2, 694.

32. Li, Z. Q.; Chen, X. T.; Xue, Z. L. CrystEngComm 2013, 15, 498.

33. Xu, L.; Yang, X.; Zhai, Z.; Hou, W. CrystEngComm 2011, 13, 7267.

34. Li, G.; Qin, F.; Yang, H.; Lu, Z.; Sun, H.; Chen, R. Eur. J. Inorg. Chem. 2012, 2012, 2508.

35. Shi, W.; Song, S.; Zhang, H. Chem. Soc. Rev. 2013, 42, 5714.

36. Fujishima, A.; Zhang, X.; Tryk, D. Surf. Sci Rep. 2008, 63, 515.

37. Qu, Y.; Duan, X. Chem. Soc. Rev. 2013, 42, 2568.

38. Kisch, H. Angew. Chem. Int. Ed. 2013, 52, 812. 